\title{
Single-dose replicating RNA vaccine induces neutralizing antibodies against SARS-CoV-2 in nonhuman
} primates

Jesse H. Erasmus ${ }^{1,2}$, Amit P. Khandhar ${ }^{2,3}$, Alexandra C. Walls ${ }^{6}$, Emily A. Hemann ${ }^{5,8}$, Megan A. O'Connor ${ }^{1,7}$, Patience Murapa ${ }^{1}$, Jacob Archer ${ }^{1,3}$, Shanna Leventhal ${ }^{4}$, Jim Fuller ${ }^{1}$, Thomas Lewis ${ }^{1,7}$, Kevin E. Draves $^{1}$, Samantha Randall ${ }^{3}$, Kathryn A. Guerriero ${ }^{7}$, Malcolm S. Duthie ${ }^{2}$, Darrick Carter ${ }^{2,3,5}$, Steven G. Reed ${ }^{3,5}$ David W. Hawman ${ }^{4}$, Heinz Feldmann ${ }^{4}$, Michael Gale, Jr. ${ }^{5,7,8}$, David Veesler ${ }^{6}$, Peter Berglund ${ }^{2}$, Deborah Heydenburg Fuller ${ }^{1,5,7 *}$.

${ }^{1}$ Department of Microbiology, University of Washington, Seattle, WA

${ }^{2}$ Host Directed Therapeutics (HDT) Bio Corp, Seattle, WA

${ }^{3}$ PAI Life Sciences, Seattle, WA

${ }^{4}$ Laboratory of Virology, Division of Intramural Research, National Institute of Allergy and Infectious

Diseases, National Institutes of Health, Hamilton, MT

${ }^{5}$ Center for Innate Immunity and Immune Disease, University of Washington, Seattle, WA

${ }^{6}$ Department of Biochemistry, University of Washington, Seattle, WA

${ }^{7}$ Washington National Primate Research Center, Seattle, WA

${ }^{8}$ Department of Immunology, University of Washington, Seattle, WA

*Corresponding author:

Deborah Heydenburg Fuller

Professor, Department of Microbiology, University of Washington, Seattle, WA

Division Chief, Infectious Diseases and Translational Medicine, Washington National Research Primate Research Center, Seattle, WA

fullerdh@uw.edu

Running title: Replicating RNA Vaccine for COVID-19

Keywords for submission: coronavirus; SARS-CoV-2; vaccine; RNA; replicon; nanoparticle; nonhuman primates. 


\section{Abstract}

2 The ongoing COVID-19 pandemic, caused by infection with SARS-CoV-2, is having a dramatic and

3 deleterious impact on health services and the global economy. Grim public health statistics highlight the

4 need for vaccines that can rapidly confer protection after a single dose and be manufactured using

5 components suitable for scale-up and efficient distribution. In response, we have rapidly developed

6 repRNA-CoV2S, a stable and highly immunogenic vaccine candidate comprised of an RNA replicon

7 formulated with a novel Lipid InOrganic Nanoparticle (LION) designed to enhance vaccine stability,

8 delivery and immunogenicity. We show that intramuscular injection of LION/repRNA-CoV2S elicits

9 robust anti-SARS-CoV-2 spike protein IgG antibody isotypes indicative of a Type $1 \mathrm{~T}$ helper response as

10 well as potent $T$ cell responses in mice. Importantly, a single-dose administration in nonhuman primates

11 elicited antibody responses that potently neutralized SARS-CoV-2. These data support further

12 development of LION/repRNA-CoV2S as a vaccine candidate for prophylactic protection from SARS-CoV-

132 infection. 
Severe acute respiratory syndrome coronavirus-2 (SARS-CoV-2) first emerged in December 2019

15 and within 3 months, Coronavirus Disease 2019 (COVID-19), caused by SARS-CoV-2 infection, was

16 declared a worldwide pandemic ${ }^{1-3}$. Coronaviruses are enveloped, single-strand positive-sense RNA

17 viruses with a large genome and open reading frames for four major structural proteins: Spike (S),

18 envelope, membrane, and nucleocapsid. The S protein mediates binding of coronaviruses to angiotensin

19 converting enzyme 2 (ACE2) on the surface of various cell types including epithelial cells of

20 the pulmonary alveolus ${ }^{4-6}$. Protection is thought to be mediated by neutralizing antibodies against the $S$

21 protein 7,8 , as most of the experimental vaccines developed against the related SARS-CoV incorporated

22 the S protein, or its receptor binding domain (RBD), with the goal of inducing robust, neutralizing

23 responses ${ }^{9-11}$. Indeed, previous reports have shown that human neutralizing antibodies protected mice

24 challenged with SARS-CoV ${ }^{12-14}$ and Middle East respiratory syndrome (MERS)-CoV ${ }^{15}$ suggesting that

25 protection against SARS-CoV-2 can be mediated through anti-S antibodies. Additionally, SARS vaccines

26 that drive Type 2 T helper (Th2) responses have been associated with enhanced lung immunopathology

27 following challenge with SARS-CoV while those with a Type $1 \mathrm{~T}$ helper (Th1)-biased immune response

28 are associated with enhanced protection in the absence of immunopathology ${ }^{16,17}$. Therefore, an

29 effective COVID-19 vaccine will likely need to induce, at the very least, Th1-biased immune responses comprised of SARS-CoV-2-specific neutralizing antibodies.

Nucleic acid vaccines have emerged as ideal modalities for rapid vaccine design, requiring only

32 the target antigen's gene sequence and removing dependence on pathogen culture (inactivated or live

33 attenuated vaccines) or scaled recombinant protein production. In addition, nucleic acid vaccines avoid

34 pre-existing immunity that can dampen immunogenicity of viral vectored vaccines. Recently, clinical

35 trials were initiated with messenger RNA (mRNA) vaccines formulated with lipid nanoparticles (LNPs)

36 and a DNA vaccine delivered by electroporation ${ }^{18}$. However, mRNA and DNA vaccines may not be able

37 to induce protective efficacy in humans after a single immunization since, similar to inactivated and

38 recombinant subunit protein vaccines, they typically require multiple administrations over an extended

39 period of time to become effective ${ }^{19}$. Virus-derived replicon RNA (repRNA) vaccines were first described

40 in 1989 and have been delivered in the forms of virus-like RNA particles (VRP), in-vitro transcribed (IVT)

41 RNA, and plasmid DNA ${ }^{20-23}$. In repRNA the open reading frame encoding the viral RNA polymerase

42 complex (most commonly from the Alphavirus genus) is intact but the structural protein genes are

43 replaced with an antigen-encoding gene ${ }^{20,24-26}$. While conventional mRNA vaccines, like that initiated in

44 a recent clinical trial, are translated directly from the incoming RNA molecules, introduction of repRNA

45 into cells initiates ongoing biosynthesis of antigen-encoding RNA that results in dramatically increased 
expression and duration that significantly enhances humoral and cellular immune responses ${ }^{27}$. In addition, repRNA vaccines mimic an alphavirus infection in that viral-sensing stress factors are triggered and innate pathways are activated through Toll-like receptors and retinoic acid inducible gene (RIG)-I to produce interferons, pro-inflammatory factors and chemotaxis of antigen-presenting cells, as well as promoting antigen cross-priming ${ }^{28}$. As a result, repRNA acts as its own adjuvant, eliciting more robust immune responses after a single dose, relative to conventional mRNA which typically requires multiple and 1,000-fold higher doses ${ }^{29}$. An effective vaccine to stop a pandemic outbreak like COVID-19 would ideally induce protective levels of immunity rapidly and after only a single dose while simultaneously

54 reducing the load on manufacturing at scale, due to a requirement for fewer and lower doses. Since repRNA vaccines often require only a single administration to be effective ${ }^{30}$, they offer considerable potential to meet this need.

A

repRNA-CoV2S
\begin{tabular}{|c|c|c|c|c|c|c|}
\hline nsP1 & nsP2 & nsP3 & nsP4 \\
\hline
\end{tabular}

B

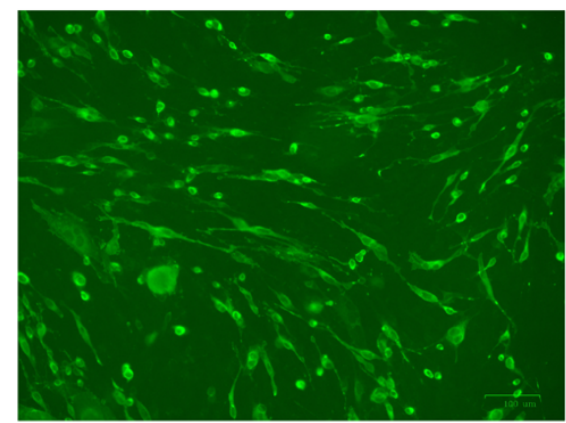

anti-v5

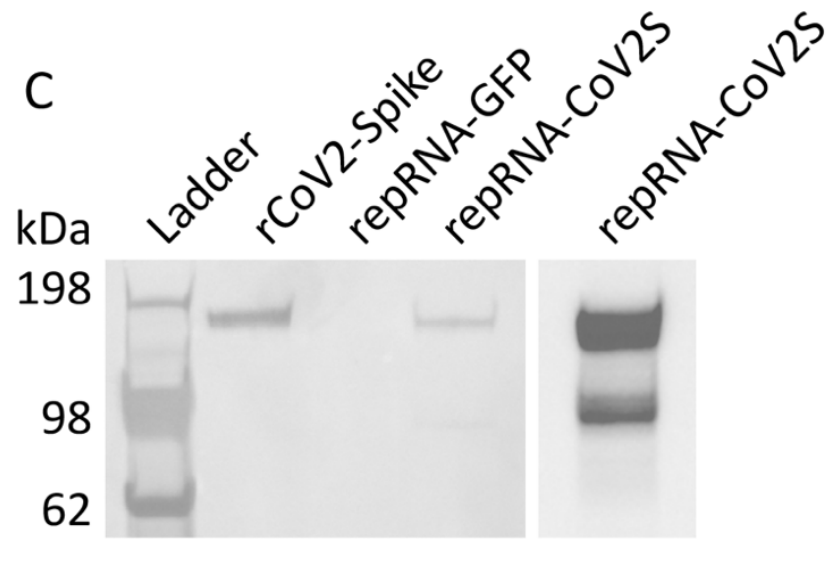

Convalescent serum anti-v5

Figure 1. repRNA-CoV2S characterization in vitro. (A) Codon-optimized full length spike (S) open reading frame, including the S1-, S2-, transmembrane- (TM), and cytoplasmic- (CD) domains, corresponding to positions 21,536 to 25,384 in SARS-CoV-2 isolate Wuhan-Hu-1 (GenBank: MN908947.3), fused to a c-terminal v5 epitope tag, was cloned into an alphavirus replicon encoding the 4 nonstructural protein (nsP1-4) genes of Venezuelan equine encephalitis virus, strain TC-83. Following RNA transcription and capping, repRNA-COV2S, was transfected into BHK cells and 24 hours later, cells were analyzed by (B) anti-v5 immunofluorescence and (C) western blot using either convalescent human serum or anti-v5 for immunodetection. Recombinant SARS-CoV2 spike protein (rCoV2-Spike) and repRNA-GFP were used as positive and negative controls, respectively. Data in B and $\mathbf{C}$ are representative of 2 independent experiments. 
Building on experience with the attenuated Venezuelan equine encephalitis virus (VEEV) TC-83 strain ${ }^{22,30-34}$, we generated repRNAs incorporating sequences from the SARS-CoV-2 Spike (S) protein, including full length S (repRNA-CoV2S) (Fig. 1A). Using immunofluorescence and western blot we demonstrated efficient expression of the v5-tagged S protein in BHK cells (Fig. 1B,C). Then, utilizing convalescent serum collected 29 days after onset of COVID-19 as an immunodetection reagent, we demonstrated endogenous expression of an S protein in BHK cells, reactive with natural SARS-CoV-2 immune sera (Fig. 1C). Next, we evaluated the ability of repRNA-CoV2S to rapidly generate antibody and T cell responses in mice when formulated with a novel Lipid InOrgainc Nanoparticle (LION) designed to enhance vaccine stability and intracellular delivery of the vaccine.

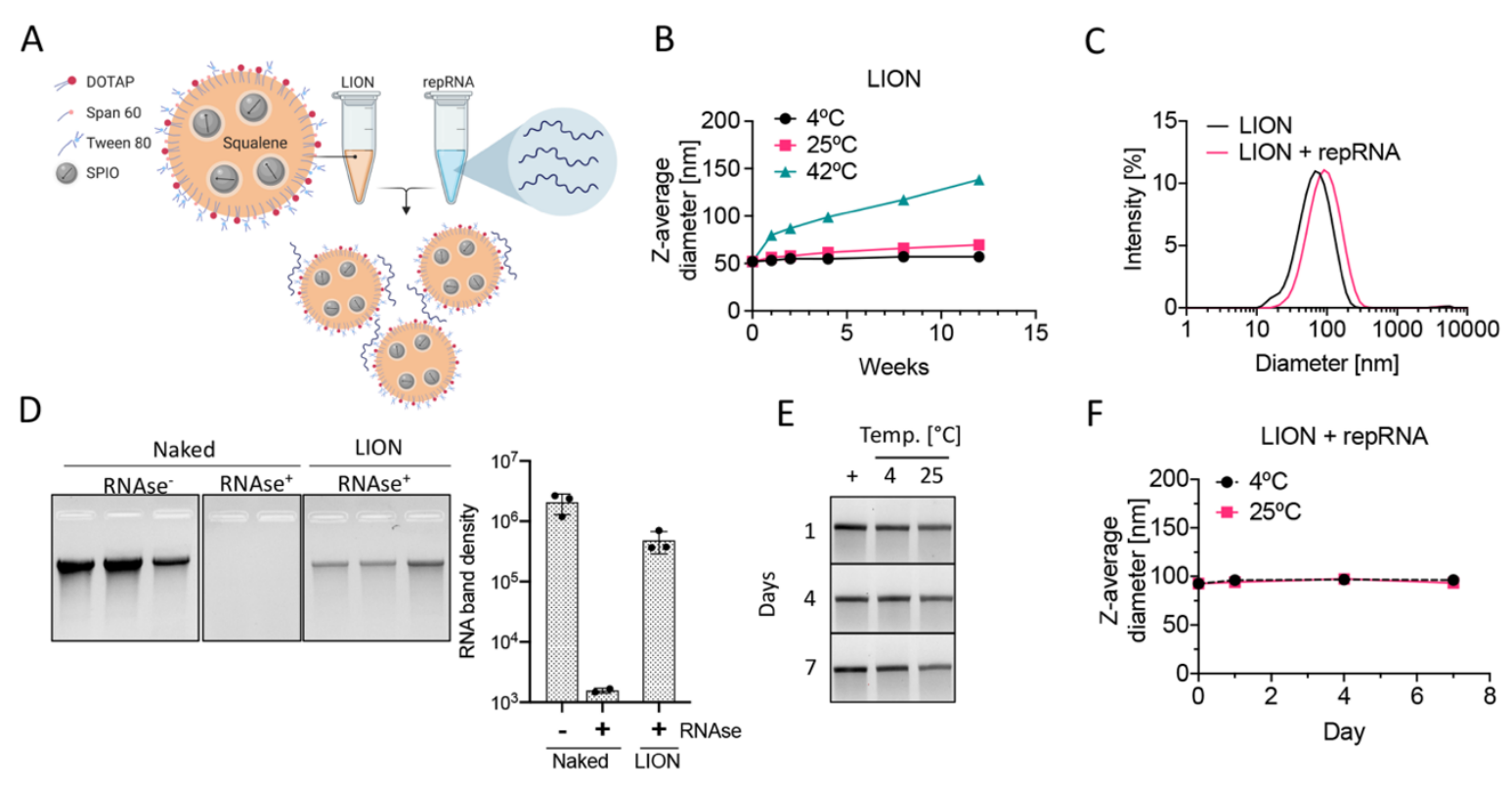

Figure 2. Lipid InOrganic Nanoparticle (LION) formulation of repRNA. (A) Graphical representation of LION and formation of vaccine complex after mixing with repRNA. (B) Time evolution of LION particle size, measured by dynamic light scattering (DLS), after storage at $4{ }^{\circ} \mathrm{C}, 25^{\circ} \mathrm{C}$ and $42^{\circ} \mathrm{C}$. (C) After mixing LION and repRNA, complex formation is confirmed by a shift in size distribution. (D) Gel electrophoresis analysis of triplicate preparations of repRNA extracted from LION after a concentrated RNase challenge shows substantial protection relative to a triplicate preparation of a dose-matched naked RNA following RNAse challenge. The formulated vaccine is stable for at least a week after mixing and storage at $4^{\circ} \mathrm{C}$ and $25^{\circ} \mathrm{C}$ as determined by (E) gel electrophoresis of repRNA extracted by phenol-chloroform treatment and (F) particle size of the complex. Data in $\mathbf{B}, \mathbf{E}$, and $\mathbf{F}$ are from a single experiment while data in $\mathbf{C}$ and $\mathbf{D}$ are representative of 3 independent experiments. Data in $\mathbf{B}, \mathbf{D}$, and $\mathbf{F}$ are shown as mean \pm s.d. of 3 technical replicates. 
71 iron replacement therapy; the unique nonlinear magnetic properties of SPIOs have also been leveraged

72 for novel use in a range of imaging, targeting and therapy applications ${ }^{37-42}$. A key component of LION is

73 the cationic lipid 1,2-dioleoyl-3-trimethylammonium propane (DOTAP), which enables electrostatic

74 association with RNA molecules when combined by a simple 1:1 (v/v) mixing step (Fig. 2A). LION has an

75 intensity-weighted average diameter of $52 \mathrm{~nm}(\mathrm{PDI}=0.2)$ measured by dynamic light scattering (DLS).

76 The formulation is colloidally stable for at least 3 months when stored at 4 and $25^{\circ} \mathrm{C}$ (Fig. 2B). When

77 mixed, electrostatic association between anionic repRNA and cationic DOTAP molecules on the surface

78 of LION promotes immediate complex formation, as confirmed by increase in particle size to an

79 intensity-weighted average diameter of $90 \mathrm{~nm}$ detected by DLS (Fig. 2C). Gel electrophoresis analysis of

80 LION-formulated repRNA molecules extracted by phenol-chloroform treatment after a concentrated

81 RNase challenge showed substantial protection from RNase-catalyzed degradation compared to

82 unformulated repRNA (Fig. 2D). To evaluate short-term stability of the vaccine, we evaluated repRNA

83 integrity and complex stability on 1, 4 and 7 days after mixing. LION maintained full integrity of the

84 repRNA molecules (Fig. 2E) and complex size (Fig. 2F) at all time points.

85 A single intramuscular immunization of C57BL/6 mice with 10 or $1 \mu \mathrm{g}$ of LION/repRNA-CoV2S

86 induced $100 \%$ seroconversion by 14 days post-immunization and robust anti-S IgG levels with mean

87 binding titers of 200 and $109 \mu \mathrm{g} / \mathrm{ml}$, respectively, and partial seroconversion (2 out of 5) at a $0.1 \mu \mathrm{g}$ dose

88 (Fig. 3A). Both the 10 and $1 \mu$ g prime-only doses induced neutralizing antibodies with mean $50 \%$

89 inhibitory concentrations (IC50) of 1:643 and 1:226, respectively, as measured by pseudovirus

90 neutralization assay (SARS-CoV-2 Wuhan-Hu-1 pseudotype). While all doses induced Th1-biased immune

91 responses indicated by significantly higher IgG2c responses when compared to IgG1 (Fig. 3C), there was

92 a trend toward higher doses inducing even more Th1-biased responses as indicated by higher IgG2c:IgG1

93 ratios (Fig. 3D). Given the potential role for T cells to contribute to protection, as seen with SARS and

94 MERS ${ }^{43-45}$, especially in the presence of waning antibody and memory B cell responses, we also

95 evaluated T cell responses to LION/repRNA-CoV2S in mice. On day 28 this same cohort of mice received

96 a second immunization and 12 days later, spleens and lungs were harvested and stimulated with an

97 overlapping 15-mer peptide library of the S protein, and IFN- $\gamma$ responses were measured by enzyme-

98 linked immune absorbent spot (ELISpot) assay. Mice receiving a 10, 1, and $0.1 \mu \mathrm{g}$ prime/boost exhibited

99 robust splenic T cell responses with mean IFN- $\gamma$ spots $/ 10^{6}$ cells of 1698,650 , and 801 , respectively (Fig.

$1003 \mathrm{E})$. Robust $\mathrm{T}$ cell responses were also detected in the lung and were similar between groups with mean

101 IFN- $\gamma$ spots $/ 10^{6}$ cells of 756,784 , and 777 , respectively (Fig. 3F). Interestingly, analysis of the specificity

102 of peptide response showed a biased response towards the S1 domain of the S protein in the spleen 
103 (Sup. Fig. 1A) whereas responses in the lung were more broadly distributed between the S1 and S2

104 domains of the S protein (Sup. Fig. 1B).

A

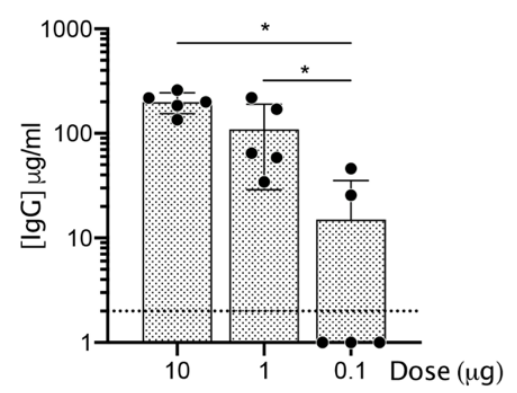

C

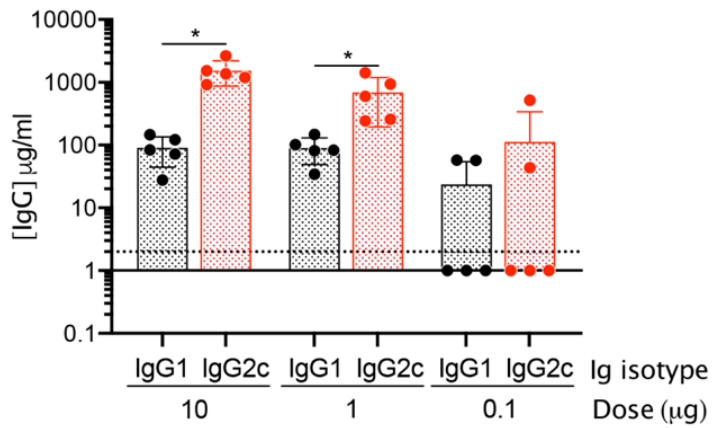

E

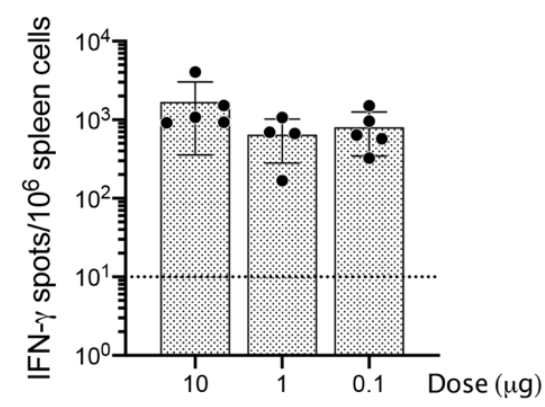

B

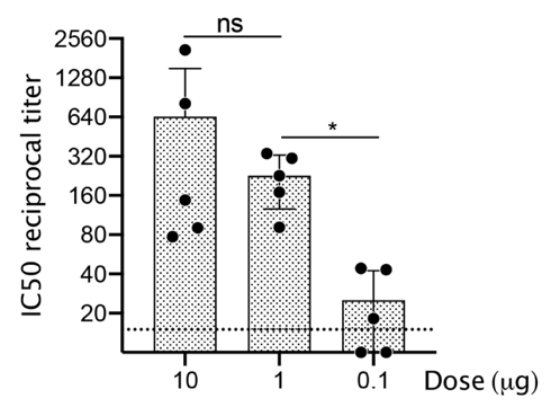

D

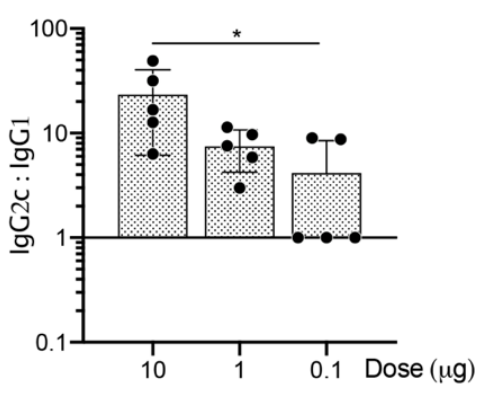

$\mathrm{F}$

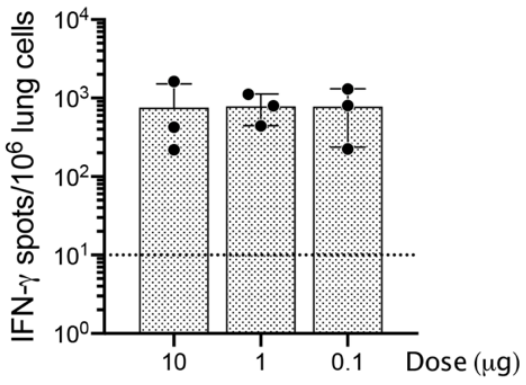

Figure 3. LION/repRNA-CoV2S induces Th1-biased and neutralizing antibodies in C57BL/6 mice. Six to eight-week old C57BL/6 mice ( $\mathrm{n}=5$ /group) received 10, 1, or $0.1 \mu \mathrm{g}$ LION/repRNA-CoV2S via the intramuscular route. Fourteen days after prime immunization, serum was harvested and $(\mathbf{A})$ anti-S IgG concentrations were determined by enzyme linked immunosorbent assay (ELISA), (B) 50\% inhibitory concentrations (IC50) determined by pseudovirus (SARS-CoV-2 Wuhan-Hu-1 pseudotype) neutralization assays, and (C) anti-S IgG1 and IgG2c concentrations and (D) ratios determined by ELISA. On day 28 , mice received a booster immunization and 12 days later, (E) spleens and (F) lungs were harvested and IFN- $\gamma$ responses were measured by enzyme-linked immune absorbent spot (ELISpot) following 18-hour stimulation with 10 peptide pools encompassing the $S$ protein and consisting of 15-mers overlapping by 11 amino acids (see Sup. Fig. 1). Data in A, C, and D are representative of $\mathbf{3}$ independent experiments while data in $\mathbf{B}, \mathbf{E}$, and $\mathbf{F}$ are from a single experiment. All data are represented as individual values as well as mean \pm s.d. ${ }^{*} p<0.05$ as determined by one-way ANOVA with Tukey's multiple comparison test. 
The elderly are among the most vulnerable to COVID-19 but immune senescence in this population poses a barrier to effective vaccination. To evaluate the effect of immune senescence on immunogenicity, we next administered 10 or $1 \mu \mathrm{g}$ of LION/repRNA-CoV2S in 2-, 8-, and 17-month old $\mathrm{BALB} / \mathrm{C}$ mice and measured anti-S IgG concentrations at 14 days after a single immunization.

109 Significantly lower antibody titers were observed in the 17-month old mice at both doses (Fig. 4A), when 110 compared to 2-and 8-month old mice, suggesting that higher doses and/or additional booster doses 111 may be required in the most immune senescent populations to induce sufficient immunity. No 112 differences were observed between the 2- and 8-month old mice. Interestingly, although BALB/C mice 113 tend to develop a more Th2 immune-biased response following vaccination ${ }^{46}$, LION/repRNA-CoV2S 114 induced ratios of IgG2a:IgG1 greater than 1 (Fig. 4B, C) in all age groups of BALB/C mice, indicating a

115 Th1-biased immune response. Given that severe, life-threatening COVID-19 appears to be more 116 common among elderly individuals, irrespective of type of Thelper response, and that severe SARS is 117 associated with skewing toward Th2 antibody profiles with an inadequate Th1 response ${ }^{16,17,43}$, the 118 ability of LION/repRNA-CoV2S to induce strong and Th1-biased responses in 8- and 2-month old mice, 119 even in the Th2-biased BALB/c strain, is a promising finding regarding the potential safety and 120 immunogenicity of this vaccine.

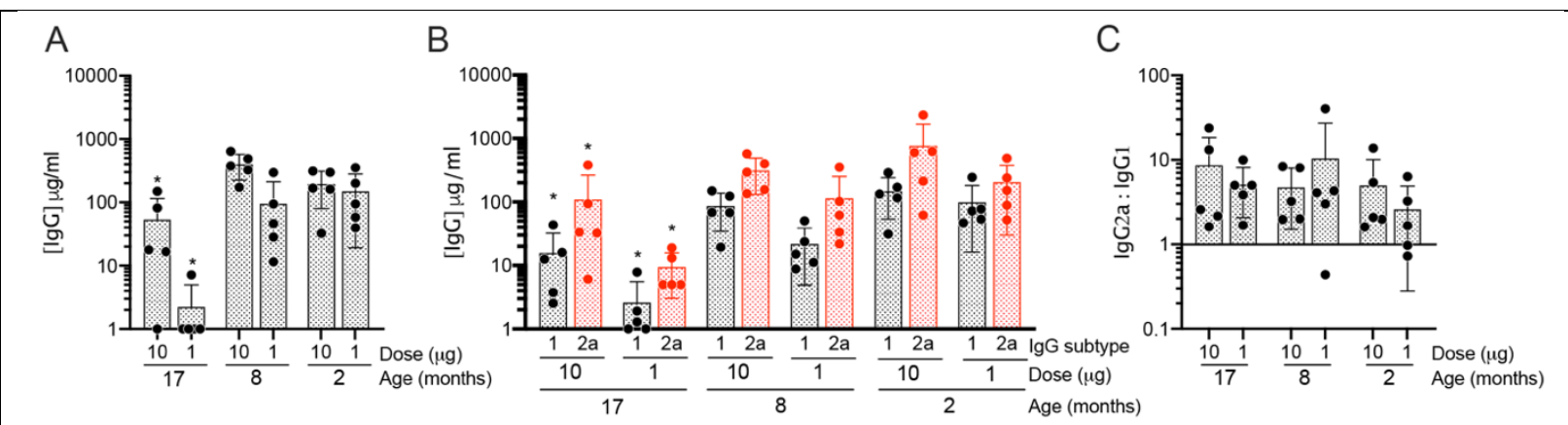

Figure 4. LION/repRNA-CoV2S induces Th1-biased antibodies in aged BALB/C mice. Two-, eight-, or seventeen-month old BALB/C mice (n-5/group) received 10 or $1 \mu \mathrm{g}$ LION/repRNA-CoV2S via the intramuscular route. Fourteen days after prime immunization, serum was harvested and $(A)$ anti-S IgG or (B) IgG1 and IgG2a concentrations and (C) ratios were determined by enzyme-linked immunosorbent assay (ELISA). Data in 17-, 8-, and 2-month old BALB/Cs are from a single experiment and data for the 2-month old BALB/Cs were replicated in a second experiment. All data are represented as individual values as well as mean \pm s.d. ${ }^{*} p<0.05$ as determined by one-way ANOVA with Tukey's multiple comparison test between the 17-month old animals and either the 8- or 2month old animals. 
124 immune responses in a nonhuman primate model that more closely resembles humans in the immune

125 response to vaccination. Three macaques received LION/repRNA-CoV2S at a single intramuscular $250 \mu \mathrm{g}$

126 dose at week 0 and two macaques received a $50 \mu$ g prime at week 0 and a boost at week 4. (Fig. 5A).

127 Blood was collected 10, 14, 28, and 42 days post vaccination to monitor vaccine safety and

128 immunogenicity. There were no observed reactions at the vaccine injection site nor adverse reactions in

129 the animals up to 42 days post-prime vaccination. Additionally, there were no abnormalities in weight or

130 temperature in the animals (Sup. Fig. 2A-B), and serum chemistries revealed no abnormal findings,

131 except for mild azotemia (mildly elevated blood urea nitrogen and creatinine) in 1 animal at 14 days

132 post vaccination (Sup. Fig. 2C). All CBC counts were unremarkable (Sup. Fig. 2D).

A

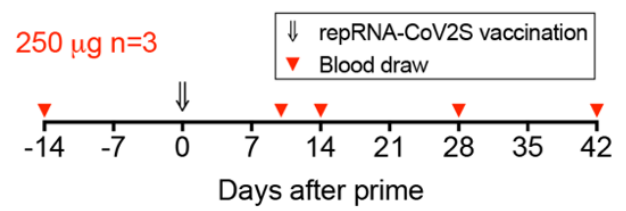

$50 \mu \mathrm{g} \mathrm{n}=2$

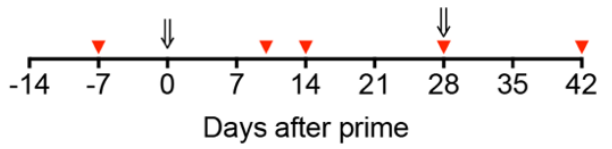

C

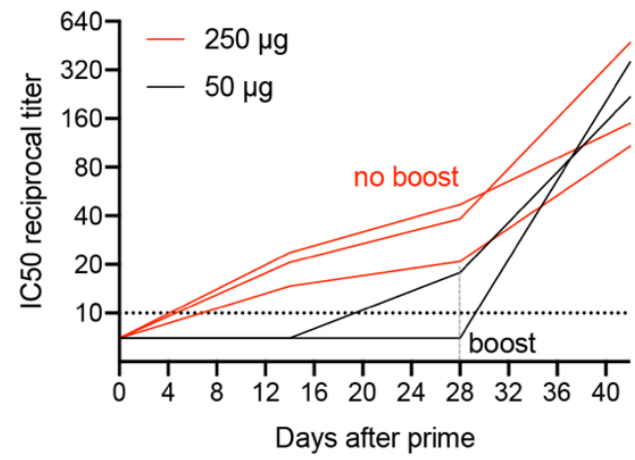

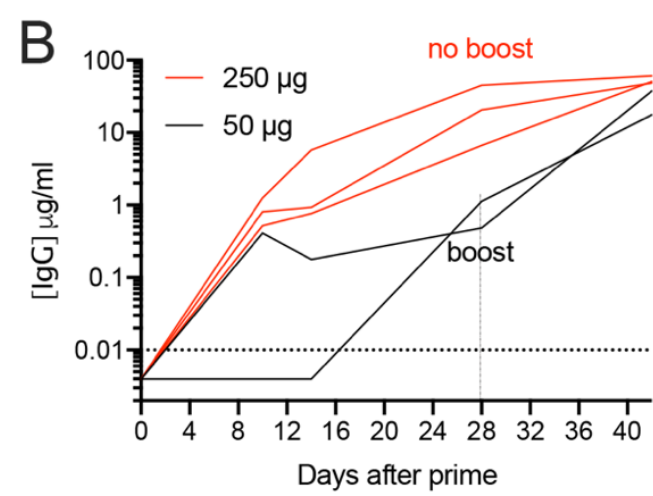

$\mathrm{D}$

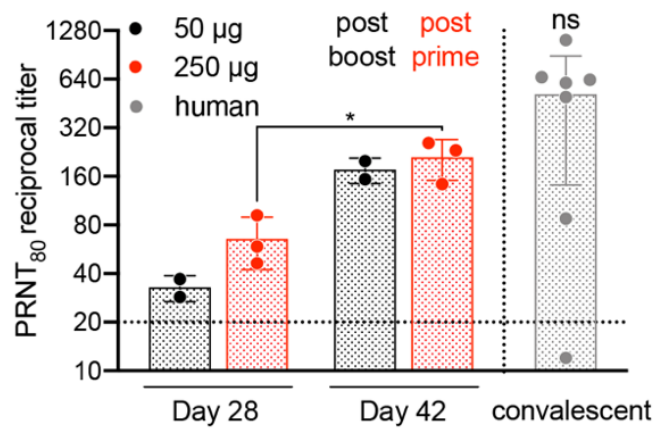

Figure 5. Single dose of LION/repRNA-CoV2S induces neutralizing antibody responses in pigtailed macaques. (A) Pigtail macaques were vaccinated with $250 \mu \mathrm{g}(\mathrm{n}=3)$ or with $50 \mu \mathrm{g}(\mathrm{n}=2)$ repRNA-CoV2$S$ via the intramuscular route and blood collected on days $10,14,28$, and 42 ; the $50 \mu$ group received a boost vaccination on day 28 and blood collected 14 days later. (B) Using pre-immunization blood draws to establish a baseline, serum anti-S IgG enzyme linked immunosorbent assays (ELISAs) were performed on the post-immunization samples as well as (C) pseudovirus (SARS-CoV-2 Wuhan-Hu-1 pseudotype) neutralization assays to determine mean $50 \%$ inhibitory concentrations (IC50) of each sample. Additionally, (D) 80\% plaque-reduction neutralizing antibody titers (PRNT 80 ) against SARSCoV2/WA/2020 isolate were measured at days 28 and 42 alongside sera from 7 convalescent human 
samples collected from confirmed COVID-19 patients (see Sup. Table 1). The experiment was performed once. Each line in $\mathbf{B}$ and $\mathbf{C}$ are representative of each individual animal. Data in $\mathbf{D}$ are reported as individual values as well as mean \pm s.d. ${ }^{*} p<0.05$ as determined by students t-test comparing $250 \mu \mathrm{g}$ groups at days 14 and 28 . There was no significant difference (ns) between mean PRNT $_{80}$ titers in all 5 animals at day 42 and titers in sera from 7 convalescent humans, as measured by Mann-Whitney U test.

135 showed that all three macaques immunized with the single $250 \mu \mathrm{g}$ dose seroconverted as early as day

13610 , with anti-S IgG concentrations continuing to increase in these 3 animals to 48,51 , and $61 \mu \mathrm{g} / \mathrm{ml}$ by 137 day 42 (Fig. 5B). Both macaques receiving $50 \mu$ g repRNA-CoV2S seroconverted after a single dose but 138 developed significantly lower antibody responses with anti-S IgG concentrations of 1 and $0.5 \mu \mathrm{g} / \mathrm{ml}$ by 139 day 28 , compared to 7,20 , and $45 \mu \mathrm{g} / \mathrm{ml}$ in the $250 \mu \mathrm{g}$ group at this same time point (Fig. 5B).

140 However, 14 days after a booster immunization, the $50 \mu \mathrm{g}$ group developed similar levels of anti-S IgG 141 concentrations ( 18 and $37 \mu \mathrm{g} / \mathrm{ml}$ ) as the $250 \mu \mathrm{g}$ prime-only group at this time point $(48,51$, and 61 $142 \mu \mathrm{g} / \mathrm{ml}$ ) (Fig. 5A). Additionally, sera from the three macaques immunized with just the single $250 \mu \mathrm{g}$ 143 dose neutralized pseudovirus (SARS-CoV-2 Wuhan-Hu-1 pseudotype) transduction of cells in vitro with 144 reciprocal IC50 titers of $1: 38,1: 20$ and $1: 47$ by day 28 with levels increasing to 1:472, 1:108, and 1:149

145 by day 42 , whereas the $50 \mu \mathrm{g}$ group achieved similar robust IC50 titers only after the booster 146 immunization reaching pseudovirus IC50 titers of 1:218 and 1:358 by day 42 (Fig. 5C and Sup. Fig. 4).

147 Sera collected 28- and 42-days post vaccination were further analyzed for neutralization of wild type

148 SARS-CoV-2/WA/2020 by $80 \%$ plaque reduction neutralization test (PRNT 80 ) and compared to 149 neutralizing titers in sera from convalescent humans collected 15-64 days following natural infection 150 (Sup. Fig. 4 and Sup. Table 1). A single immunization with 50 and $250 \mu \mathrm{g}$ of LION/repRNA-CoV2S 151 induced mean PRNT $_{80}$ titers of $1: 32$ and 1:66 by day 28 , respectively. By Day 42 , mean PRNT 80 titers 152 significantly increased to 1:176 after a booster immunization in the $50 \mu$ group and to 1:211 in the 153 prime-only $250 \mu$ g group, (Fig. 5D and Sup. Fig. 4). Importantly, all 5 macaques developed PRNT 80 titers 154 within the same range as titers measured in the seven convalescent humans $(<1: 20$ to $1: 1280$, collected 15515 to 64 days post onset) and there was no significant difference in mean neutralizing titers between all 1565 vaccinated macaques (1:197) and convalescent humans (1:518) ( $P=0.27$, Fig. 5D, Sup. Fig. 4, and Sup.

157 Table 1). Recently, serum neutralizing titers, measured as the IC50 titer that neutralized SARS-CoV-2 by

$15850 \%$ tissue culture infectious dose $\left(\mathrm{TCID}_{50}\right)$, were reported in rhesus macaques that were either re159 infected ${ }^{47}$ or challenged after vaccination with an inactivated SARS-CoV-2 vaccine ${ }^{48}$. In the former 160 report, IC50 titers as low as 1:8 were associated with protection from re-infection while in the latter, 
161 IC50 titers as low as 1:50 were associated with reduced viral load and protection from lung pathology.

162 These data suggest that a $250 \mu \mathrm{g}$ prime-only or a $50 \mu \mathrm{g}$ prime/boost immunization with the

163 LION/repRNA-CoV2 vaccine may be able to induce levels of neutralizing antibodies sufficient to protect

164 nonhuman primates from infection and disease. Studies are now underway to evaluate protective

165 efficacy.

166 RepRNA vaccines against a variety of infectious diseases and cancers have been shown to be

167 safe and potent in clinical trials ${ }^{49-52}$, and the cell-free and potentially highly scalable manufacturing

168 process of repRNA when used with effective synthetic formulations, such as LION, present further

169 benefits over mRNA. The two-vial approach provides a significant manufacturing and distribution

170 advantage over LNP formulations that encapsulate RNA, as the vaccine can be stockpiled and combined

171 onsite as needed. Additionally, we demonstrated that LION/repRNA-CoV-2 induces robust S-specific T

172 cell responses in mice. Given the relatively recent emergence of SARS-CoV-2, we can only speculate

173 based on limited knowledge from previous reports of coronavirus infection as to how $T$ cell responses

174 may contribute to protection from infection and disease. Following natural infection of humans with

175 the related SARS-CoV, neutralizing antibody and memory B cell responses in some individuals are

176 reported to be short lived ( 3 years) while memory T cells persist at least 6 years ${ }^{53}$, suggesting a

177 potential role for $\mathrm{T}$ cells in long term responses especially in those who lack robust memory B cell

178 responses. Additionally, anti-S T-cell responses to the related SARS- and MERS-CoVs contribute towards

179 viral clearance in normal as well as aged mice infected with SARS- or MERS-CoV, respectively ${ }^{43-45}$.

180 Together, our results demonstrate a significant potential for LION/repRNA-CoV2S, which will

181 enter clinical development under the name HDT-301, to induce rapid immune protection from SARS-

182 CoV-2 infection. A scalable and widely-distributed vaccine capable of inducing robust immunity in both

183 young and aged populations against SARS-CoV-2 infection in a single shot would provide immediate

184 and effective containment of the pandemic. Critically, the vaccine induced Th1-biased antibody and T

185 cell responses in both young and aged mice, an attribute that has been associated with improved

186 recovery and milder disease outcomes in SARS-CoV-infected patients ${ }^{54}$. Together, these results support

187 further development of LION/repRNA-CoV2S as a vaccine candidate for protection from COVID19.

\section{Acknowledgements}

190 The authors would like to thank Brieann Brown, Solomon Wangari, Joel Ahrens, Naoto Iwayama, 191 and William Garrison for their technical assistance with the pigtail macaque study as well as Dr. Helen

192 Chu and Sarah Bowell for donating remnant, de-identified convalescent human sera from confirmed 
193 COVID-19 patients. Additionally, the authors thank Dr. Scott Weaver at the University of Texas Medical

194 Branch for providing the plasmid vector encoding VEEV-TC83, and the Institute for Protein Design at the 195 University of Washington for providing recombinant SARS-CoV-2 spike protein.

196 This work was funded by P510D010425 (Washington National Primate Research Center),

197 NIH/NIAID Centers of Excellence for Influenza Research and Surveillance contract HHSN27220140006C

198 (JHE), and HDT Biotech internal funds. Additional support from the University of Washington Center for

199 Innate Immunity and Immune Disease, NIH/NIAID contract 75N93019C00037 (MD), NIH/NIAID contract

20075 N93019C00008 (APK), the NIGMS/NIH R01GM120553 (DV), NIAID/NIH HHSN272201700059C (DV), a

201 Pew Biomedical Scholars Award (DV), an Investigators in the Pathogenesis of Infectious Disease Award

202 from the Burroughs Wellcome Fund (DV), and the intramural research program of NIAID, NIH (DH, SL,

203 HF). JHE is a Washington Research Foundation Postdoctoral fellow and is also supported by NIH

204 1F32Al136371. The content is solely the responsibility of the authors and does not necessarily represent 205 the official views of the funders.

\section{Conflict of interest statement}

207 JHE, APK, JA, MD, DC, PB, MG, and SGR have equity interest in HDT Biocorp. JHE, PB, JF, DHF, HF and DH 208 are inventors on a patent filing pertaining to repRNA-CoV2S. JHE, APK, DC, MD and SGR are inventors on 209 a patent filing pertaining to LION formulation. 


\section{References}

211 1. Lu, H., Stratton, C. W. \& Tang, Y.-W. Outbreak of pneumonia of unknown etiology in Wuhan,

212 China: The mystery and the miracle. J. Med. Virol. 92, 401-402 (2020).

2132 2. Wu, F. et al. A new coronavirus associated with human respiratory disease in China. Nature 579, 214 265-269 (2020).

215 3. Wang, C., Horby, P. W., Hayden, F. G. \& Gao, G. F. A novel coronavirus outbreak of global health 216 concern. Lancet (London, England) 395, 470-473 (2020).

217 4. Hamming, I. et al. Tissue distribution of ACE2 protein, the functional receptor for SARS 218 coronavirus. A first step in understanding SARS pathogenesis. J. Pathol. 203, 631-637 (2004).

219 5. Letko, M., Marzi, A. \& Munster, V. Functional assessment of cell entry and receptor usage for 220 SARS-CoV-2 and other lineage B betacoronaviruses. Nat. Microbiol. 5, 562-569 (2020).

221 6. Walls, A. C. et al. Structure, Function, and Antigenicity of the SARS-CoV-2 Spike Glycoprotein. Cell 181, 281-292.e6 (2020).

223 7. Walls, A. C. et al. Unexpected Receptor Functional Mimicry Elucidates Activation of Coronavirus Fusion. Cell 176, 1026-1039.e15 (2019).

8. Pinto, D. et al. Structural and functional analysis of a potent sarbecovirus neutralizing antibody. bioRxiv (2020) doi:10.1101/2020.04.07.023903.

10. Jiang, S., He, Y. \& Liu, S. SARS vaccine development. Emerg. Infect. Dis. 11, 1016-1020 (2005).

231 11. Du, L. et al. The spike protein of SARS-CoV--a target for vaccine and therapeutic development. Nat. Rev. Microbiol. 7, 226-236 (2009).

12. Menachery, V. D. et al. SARS-like WIV1-CoV poised for human emergence. Proc. Natl. Acad. Sci. U. S. A. 113, 3048-3053 (2016).

235 13. Rockx, B. et al. Structural basis for potent cross-neutralizing human monoclonal antibody protection against lethal human and zoonotic severe acute respiratory syndrome coronavirus challenge. J. Virol. 82, 3220-3235 (2008).

238 14. Traggiai, E. et al. An efficient method to make human monoclonal antibodies from memory B cells: potent neutralization of SARS coronavirus. Nat. Med. 10, 871-875 (2004).

240 15. Corti, D. et al. Prophylactic and postexposure efficacy of a potent human monoclonal antibody against MERS coronavirus. Proc. Natl. Acad. Sci. U. S. A. 112, 10473-10478 (2015). 
242 16. Tseng, C.-T. et al. Immunization with SARS coronavirus vaccines leads to pulmonary

243 immunopathology on challenge with the SARS virus. PLoS One 7, e35421 (2012).

244 17. Honda-Okubo, Y. et al. Severe Acute Respiratory Syndrome-Associated Coronavirus Vaccines

$245 \quad$ Formulated with Delta Inulin Adjuvants Provide Enhanced Protection while Ameliorating Lung

246 Eosinophilic Immunopathology. J. Virol. 89, 2995-3007 (2015).

247 18. Thanh Le, T. et al. The COVID-19 vaccine development landscape. Nature reviews. Drug discovery $248 \quad$ (2020) doi:10.1038/d41573-020-00073-5.

249 19. Shang, W., Yang, Y., Rao, Y. \& Rao, X. The outbreak of SARS-CoV-2 pneumonia calls for viral $250 \quad$ vaccines. npj Vaccines 5, 18 (2020).

251 20. Xiong, C. et al. Sindbis virus: an efficient, broad host range vector for gene expression in animal 252 cells. Science (80-. ). 243, 1188 LP - 1191 (1989).

253 21. Zhou, X. et al. Self-replicating Semliki Forest virus RNA as recombinant vaccine. Vaccine 12, 15102541514 (1994).

255 22. Ljungberg, K. \& Liljeström, P. Self-replicating alphavirus RNA vaccines. Expert Rev. Vaccines 18, 125618 [Epub ahead of print] (2014).

257 23. Frolov, l. et al. Alphavirus-based expression vectors: strategies and applications. Proc. Natl. Acad. Sci. 93, 11371-11377 (2002).

24. Bredenbeek, P. J., Frolov, I., Rice, C. M. \& Schlesinger, S. Sindbis virus expression vectors: packaging of RNA replicons by using defective helper RNAs. J. Virol. 67, 6439-6446 (1993).

25. Liljestrom, P. \& Garoff, H. A new generation of animal cell expression vectors based on the

27. Berglund, P., Smerdou, C., Fleeton, M. N., Tubulekas, I. \& Liljestrom, P. Enhancing immune Semliki Forest virus replicon. Biotechnology. (N. Y). 9, 1356-1361 (1991).

26. Pushko, P. et al. Replicon-helper systems from attenuated Venezuelan equine encephalitis virus: responses using suicidal DNA vaccines. Nat. Biotechnol. 16, 562-565 (1998).

28. Jensen, S. \& Thomsen, a. R. Sensing of RNA Viruses: a Review of Innate Immune Receptors Involved in Recognizing RNA Virus Invasion. J. Virol. 86, 2900-2910 (2012).

29. Vogel, A. B. et al. Self-Amplifying RNA Vaccines Give Equivalent Protection against Influenza to

272 30. Strauss, J. H. \& Strauss, E. G. The alphaviruses: gene expression, replication, and evolution. 
274 31. Kinney, R. M. et al. Attenuation of Venezuelan equine encephalitis virus strain TC-83 is encoded by the 5'-noncoding region and the E2 envelope glycoprotein. J. Virol. 67, 1269-1277 (1993).

32. Atasheva, S. et al. Pseudoinfectious Venezuelan Equine Encephalitis Virus: a New Means of Alphavirus Attenuation. J. Virol. 87, 13 (2016).

33. Erasmus, J. H. et al. A Nanostructured Lipid Carrier for Delivery of a Replicating Viral RNA Provides Single, Low-Dose Protection against Zika. Mol. Ther. 26, 1-16 (2018).

34. Duthie, M. S. et al. Heterologous Immunization With Defined RNA and Subunit Vaccines Enhances T Cell Responses That Protect Against Leishmania donovani. Front. Immunol. 9, 2420 (2018).

35. Calabro, S. et al. The adjuvant effect of MF59 is due to the oil-in-water emulsion formulation,

36. Desbien, A. L. et al. Squalene emulsion potentiates the adjuvant activity of the TLR4 agonist, GLA, via inflammatory caspases, IL-18, and IFN-ү. Eur. J. Immunol. 45, 407-417 (2015).

37. Yu, E. Y. et al. Magnetic Particle Imaging for Highly Sensitive, Quantitative, and Safe in Vivo Gut Bleed Detection in a Murine Model. ACS Nano 11, 12067-12076 (2017).

38. Khandhar, A. P. et al. Evaluation of PEG-coated iron oxide nanoparticles as blood pool tracers for preclinical magnetic particle imaging. Nanoscale 9, 1299-1306 (2017).

39. Bauer, L. M., Situ, S. F., Griswold, M. A. \& Samia, A. C. S. High-performance iron oxide

40. Zhao, Y., Zhao, X., Cheng, Y., Guo, X. \& Yuan, W. Iron Oxide Nanoparticles-Based Vaccine Delivery for Cancer Treatment. Mol. Pharm. 15, 1791-1799 (2018).

41. Zanganeh, S. et al. Iron oxide nanoparticles inhibit tumour growth by inducing pro-inflammatory macrophage polarization in tumour tissues. Nat. Nanotechnol. 11, 986-994 (2016).

42. Khandhar, A. P. et al. Evaluating size-dependent relaxivity of PEGylated-USPIOs to develop gadolinium-free T1 contrast agents for vascular imaging. J. Biomed. Mater. Res. A 106, 24402447 (2018).

43. Zhao, J., Zhao, J. \& Perlman, S. T cell responses are required for protection from clinical disease and for virus clearance in severe acute respiratory syndrome coronavirus-infected mice. J. Virol. 84, 9318-9325 (2010).

44. Channappanavar, R., Zhao, J. \& PerIman, S. T cell-mediated immune response to respiratory 
coronaviruses. Immunol. Res. 59, 118-128 (2014).

307 45. Channappanavar, R., Fett, C., Zhao, J., Meyerholz, D. K. \& Perlman, S. Virus-Specific Memory CD8 T Cells Provide Substantial Protection from Lethal Severe Acute Respiratory Syndrome Coronavirus Infection. J. Virol. 88, 11034-11044 (2014).

310 46. Mills, C. D., Kincaid, K., Alt, J. M., Heilman, M. J. \& Hill, A. M. M-1/M-2 Macrophages and the Th1/Th2 Paradigm. J. Immunol. 164, 6166-6173 (2000).

312 47. Bao, L. et al. Reinfection could not occur in SARS-CoV-2 infected rhesus macaques. bioRxiv 2020.03.13.990226 (2020) doi:10.1101/2020.03.13.990226.

314 48. Gao, Q. et al. Development of an inactivated vaccine candidate for SARS-CoV-2. Science (80-. ). 1932, eabc1932 (2020).

316 49. Bernstein, D. I. et al. Randomized, double-blind, Phase 1 trial of an alphavirus replicon vaccine for cytomegalovirus in CMV seronegative adult volunteers. Vaccine 28, 484-493 (2009).

318 50. Hubby, B. et al. Development and preclinical evaluation of an alphavirus replicon vaccine for 319 influenza. Vaccine 25, 8180-8189 (2007).

320 51. Morse, M. A. et al. Phase I study of alphaviral vector (AVX701) in colorectal cancer patients: comparison of immune responses in stage III and stage IV patients. J. Immunother. Cancer $\mathbf{3}$,

323 52. Reap, E. A. et al. Development and preclinical evaluation of an alphavirus replicon particle 324 vaccine for cytomegalovirus. Vaccine 25, 7441-7449 (2007).

325 53. Tang, F. et al. Lack of Peripheral Memory B Cell Responses in Recovered Patients with Severe Acute Respiratory Syndrome: A Six-Year Follow-Up Study. J. Immunol. 186, 7264-7268 (2011).

327 54. Li, C. K. et al. T Cell Responses to Whole SARS Coronavirus in Humans. J. Immunol. 181, 5490$328 \quad 5500$ (2008). 


\section{Supplementary Material}

\section{Materials and Methods}

333 SARS-CoV-2 repRNA vaccine production and qualification. Codon optimized gene sequences

334 for SARS-CoV-2 full S corresponding to positions 21,536 to 25,384 in SARS-CoV-2 isolate Wuhan-

335 Hu-1 (GenBank: MN908947.3) fused to a c-terminal v5 epitope tag was synthesized as double

336 stranded DNA fragments (IDT) and cloned into a plasmid vector encoding the 5' and 3'

337 untranslated regions as well as the nonstructural open reading frame of Venezuelan equine

338 encephalitis virus, strain TC-83, between PfIFI and Sacll sites by Gibson assembly (SGI-DNA).

339 Clones were then sanger sequenced and prepped for RNA production as follows. Template DNA

340 was linearized by enzymatic digestion with Notl followed by phenol chloroform treatment and

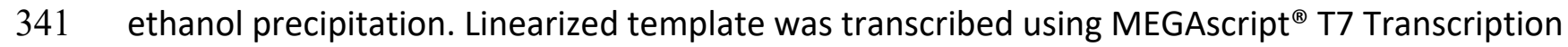

342 Kit (Invitrogen, Carlsbad, CA) followed by capping with NEB Vaccinia Capping System as

343 previously described ${ }^{1}$. To qualify the vaccine candidate in vitro, Baby Hamster Kidney (BHK)

344 cells (ATCC) were transfected with repRNA or mock transfected using Trans/T-mRNA

345 transfection kit (Mirus Bio) and cells analyzed 24 hours later by immunofluorescence using a

346 mouse anti-v5 AF488 secondary antibody (Invitrogen). Additionally, BHK cells were transfected

347 with repRNA-CoV2S and repRNA-GFP and cell lysates were collected 24 hours later for analysis

348 by SDS-PAGE and by western blot using recombinant SARS-CoV-2 S protein as a positive control.

349 To detect repRNA-mediated protein expression following transfer to nitrocellulose membrane,

350 anti-v5-HRP or convalescent human serum collected 29 days after onset of PCR-confirmed

351 COVID-19 followed by anti-human Ig-HRP secondary antibody (Southern Biotech) was used.

352 LION formulation. To protect the RNA replicons from degradation, we partnered them with a

353 Lipid InOrganic Nanoparticle (LION) formulation that consists of inorganic superparamagnetic

354 iron oxide (SPIO) nanoparticles within a hydrophobic squalene core to enhance formulation

355 stability. LIONs comprise $37.5 \mathrm{mg} / \mathrm{ml}$ squalene (Millipore Sigma), $37 \mathrm{mg} / \mathrm{ml}$ Span ${ }^{\circledR} 60$ (Millipore

356 Sigma), 37 mg/ml Tween ${ }^{\circledR} 80$ (Fisher Chemical), 30 mg/ml DOTAP chloride (Corden Pharma), 0.2

$357 \mathrm{mg} / \mathrm{ml} 15 \mathrm{~nm}$ oleic acid-coated iron oxide nanoparticles (Ocean Nanotech, San Diego, CA) and

$35810 \mathrm{mM}$ sodium citrate dihydrate (Fisher Chemical). LION particles were manufactured by 
combining the iron oxide nanoparticles with the oil phase (Squalene, Span 60, and DOTAP) and sonicating for 30 minutes in a $65^{\circ} \mathrm{C}$ water bath. Separately, the aqueous phase, containing Tween 80 and sodium citrate dihydrate solution in water, was prepared with continuous stirring

362 until all components were dissolved. The oil and aqueous phases were then mixed and

363 emulsified using a VWR 200 homogenizer (VWR International) and the crude colloid was

364 subsequently processed by passaging through a microfluidizer at 20,000 psi with a LM10

365 microfluidizer equipped with a H10Z-100 $\mu$ m ceramic interaction chamber (Microfluidics) until

366 the z-average hydrodynamic diameter - measured by dynamic light scattering (Malvern

367 Zetasizer Nano S) - reached $50 \pm 5 \mathrm{~nm}$ with a 0.2 polydispersity index. The microfluidized LION

368 was terminally filtered with a $200 \mathrm{~nm}$ pore-size polyethersulfone (PES) filter and stored at 2-

$3698^{\circ} \mathrm{C}$.

370 RNase protection. Replicon RNA was complexed with LION formulations and placed on ice for

$37130 \mathrm{~min}$. After diluting the complex using nuclease-free water, complexes containing $1 \mu \mathrm{g}$ of

372 repRNA at $20 \mu \mathrm{g} / \mathrm{mL}$ were treated with $50 \mathrm{ng}$ of RNase A (Thermo Scientific) for 30 min at room

373 temperature, followed by an incubation with $5 \mu \mathrm{g}$ of recombinant Proteinase K (Thermo

374 Scientific) for $10 \mathrm{~min}$ at $55^{\circ} \mathrm{C}$. RNA was then extracted using an equal volume of $25: 24: 1$

375 phenol:chloroform:isoamyl alcohol (Invitrogen). After vortexing, samples were centrifuged at

$37617,000 \times g$ for $15 \mathrm{~min}$. The supernatant was collected and mixed 1:1 with Glyoxal load dye

377 (Invitrogen) and heated at $50^{\circ} \mathrm{C}$ for $15 \mathrm{~min}$. The equivalent of $200 \mathrm{ng}$ of RNA was loaded and run 378 on a denatured $150 \mathrm{~mL}$ 1\% agarose gel in Northern Max Gly running buffer (Invitrogen) at $120 \mathrm{~V}$

379 for 45 min. Gels were imaged using a ChemiDoc MP imaging system (BioRad). The intensity of

380 the intact RNA band was compared to phenol:chloroform:isoamyl extracted RNA from

381 complexes that were not subjected to RNase and Proteinase K treatment.

Mouse immunizations. All mouse experiments were conducted in accordance with procedures

384 approved by the institutional animal care and use committee. Female C57BL/6 or BALB/C mice

385 (purchased from Charles River, Wilmington, MA) were maintained in specific pathogen-free 386 conditions and entered experiments at 6-12 weeks of age unless otherwise indicated. Mice

387 were immunized by intramuscular injection of vaccine delivered in a total volume of $50 \mu l$ in the 
thigh.

Pigtail macaque study. Five adult male pigtail macaques were used in these studies (aged 3-6

391 years, weight 5-13 kg). All animals received a previous Hepatitis B virus (HBV) DNA and protein

392 vaccine regimen, comprised of HBV core and surface antigens and anti-CD180 ${ }^{2}$, and were re-

393 enrolled in this study in response to the SARS-CoV-2 pandemic. All animals were housed at the

394 Washington National Primate Research Center (WaNPRC), an accredited by the American

395 Association for the Accreditation of Laboratory Animal Care International (AAALAC), and as

396 previously described ${ }^{3}$. All procedures performed on the animals were with the approval of the

397 University of Washington's Institutional Animal Care and Use Committee (IACUC).

Blood was collected at baseline (week -2 or -1 ), and at days 10, 14, 28, and 42 postprime vaccination (Fig. 5A). Blood was also collected 10 days post-boost (38 days post-prime) in the $50 \mu \mathrm{g}$ vaccinated animals. Serum and plasma were collected and PBMCs were isolated from whole blood as previously described ${ }^{4}$. Animals were sedated with an intramuscular injection $(10 \mathrm{mg} / \mathrm{kg})$ of ketamine (Ketaset ${ }^{\circledR}$; Henry Schein) prior to blood collection or vaccination. Animals were observed daily for general health (activity, appetite) and for evidence of reactogenicity at the vaccine inoculation site (swelling, redness). They also received full physical exams including temperature and weights measurements at each study timepoint. None of the

Pigtail macaque immunization. LION and repRNA-CoV2S were complexed at a nitrogen-to-

409 phosphate molar ratio of 15 in $10 \mathrm{mM}$ sodium citrate and $20 \%$ sucrose buffer on ice and 410 incubated for at least 30 minutes. The $50 \mu \mathrm{g}$ vaccine was delivered intramuscularly into the 411 quadriceps muscle with one $250 \mu$ injection on weeks 0 and 4 . The $250 \mu \mathrm{g}$ vaccine was 412 delivered intramuscularly with five $250 \mu$ injections over 4 muscles, 2 in the right quadriceps, 1 413 in the left quadricep, and 1 each in the left and right deltoids on week 0 . All injection sites were 414 shaved prior to injection and monitored post-injection for any signs of local reactogenicity. 
417 Coulter AU 680/5812 system and complete blood counts were determined on a Sysmex XN9000

418 analyzer by the University of Washington Department of Laboratory Medicine.

Antigen-specific antibody responses. Blood was collected from the retro-orbital sinus of

421 immunized mice, or venipuncture of anesthetized macaques, and serum prepared. Antigen-

422 specific IgG, IgG1, IgG2a, and IgG2c responses were detected by enzyme linked immunosorbent 423 assay (ELISA) using a previously described recombinant SARS-CoV-2 S as the capture antigen ${ }^{5}$.

424 ELISA plates (Nunc, Rochester, NY) were coated with $1 \mu \mathrm{g} / \mathrm{ml}$ antigen or with serial dilutions of

425 purified polyclonal IgG from mouse our monkeys to generate a standard curve in 0.1 M PBS

426 buffer and blocked with 0.2\% BSA-PBS. Then, in consecutive order, washes in PBS/Tween,

427 serially diluted serum samples, anti-mouse or-monkey IgG, IgG1, IgG2a, or IgG2c-HRP (Southern

428 Biotech, Birmingham, AL) and TMB then $\mathrm{HCL}$ were added to the plates. Plates were analyzed at

429 405nm (ELx808, Bio-Tek Instruments Inc, Winooski, VT). Absorbance values from the linear

430 segment of each serum dilution curve was used to interpolate the standard curve and calculate

431 the IgG concentration present in each sample.

SARS-CoV-2 pseudovirus neutralization. Murine leukemia virus (MLV)-based SARS-CoV-2 S-

434 pseudotyped viruses were prepared as previously described ${ }^{5,6}$. In brief, HEK293T cells were co-

435 transfected with a SARS-CoV-2 (based on Wuhan-Hu-1 isolate) S-encoding plasmid, an MLV

436 Gag-Pol packaging construct, and the MLV transfer vector encoding a luciferase reporter using

437 the Lipofectamine 2000 transfection reagent (Life Technologies) according to the

438 manufacturer's instructions. Cells were incubated for 5 hours at $37^{\circ} \mathrm{C}$ with $8 \% \mathrm{CO} 2$ with DNA,

439 lipofectamine, and OPTIMEM transfection medium. Following incubation DMEM containing

$440 \quad 10 \%$ FBS was added for 72 hours. Pseudovirus was then concentrated using a 30kDa Amicon

441 concentrator for 10 minutes at 3,000 $\mathrm{x} g$ and frozen at $-80 \mathrm{C}$.

442 BHK cells were plated in 96 well plates for 16-24 hours prior to being transfected with

443 human ACE2 using standard lipofectamine 2000 protocol and incubated for 5 hours at $37^{\circ} \mathrm{C}$

444 with 8\% CO2 with DNA, lipofectamine, and OPTIMEM transfection medium. Following

445 incubation, DMEM containing $20 \%$ FBS was added in equal volume to the OPTIMEM 
446 transfection media for 16-24 hours. Concentrated pseudovirus with or without serial dilution of

447 antibodies was incubated for 1 hour at room temperature and then added to the wells after

448 washing $3 \mathrm{X}$ with DMEM and removing all media. After 2-3 hours, equal volumes of DMEM

449 containing 20\% FBS and 2\% PenStrep was added to the cells for 48 hours. Following 48 hours of

450 infection, equal volume of One-Glo-EX (Promega) was added to the cells and incubated in the

451 dark for 5-10 minutes prior to reading on a Varioskan LUX plate reader (ThermoFisher).

452 Measurements were done in duplicate and relative luciferase units (RLU) were recorded.

454 SARS-CoV-2 neutralization. Three-fold (pigtail macaque) or four-fold (human) serial dilutions of

455 heat inactivated serum and 600 plaque-forming units (PFU)/ml solution of SARS-CoV-2/WA/20

456 (BEI resources) were mixed 1:1 in DPBS (Fisher Scientific) + 0.3\% gelatin (Sigma G7041) and

457 incubated for $30 \mathrm{~min}$ at $37^{\circ} \mathrm{C}$. Serum/virus mixtures were added in duplicate, along with virus

458 only and mock controls, to Vero E6 cells (ATCC) in a 12-well plate and incubated for $1 \mathrm{hr}$ at $37^{\circ} \mathrm{C}$.

459 Following adsorption, plates were washed once with DPBS and overlayed with a 1:1 mixture of

460 Avicel RC-591 (FMC) + 2 x MEM (ThermoFisher) supplemented with 4\% heat-inactivated FBS

461 and Penicillin/Streptomycin (Fisher Scientific). Plates were then incubated for 2 days at $37^{\circ} \mathrm{C}$.

462 Following incubation, overlay was removed and plates were washed once with DPBS and then

$46310 \%$ formaldehyde (Sigma-Aldrich) in DPBS was added to cells and incubated for 30 minutes at

464 room temp. Plates were washed again with DPBS and stained with 1\% crystal violet (Sigma-

465 Aldrich) in 20\% EtOH (Fisher Scientific). Plaques were enumerated and percent neutralization

466 was calculated relative to the virus-only control.

Mouse IFN-p ELISPOT. Spleen and lung lymphocytes were isolated from mice 12 days after the

469 second vaccination. MIAPS4510-Multiscreen plates (Millipore) were coated with rat anti mouse

470 IFN-gamma capture antibody (BD) in PBS and incubated overnight at $4^{\circ} \mathrm{C}$. The plates were

471 washed in PBS and then blocked (2h, RT) with RPMI medium (Invitrogen) containing 10\% heat

472 inactivated fetal calf serum (Gibco). Lung and spleen cells were plated at $5 \times 10^{5}$ and $2.5 \times 10^{5}$

473 cells/well and stimulated with the SARS-Cov2 S peptide pools (11aa overlapping 15 mer

474 peptides from Genscript) at $1.5 \mu \mathrm{g} / \mathrm{ml} /$ peptide and cultured for 20 hours $\left(37^{\circ} \mathrm{C}, 5 \% \mathrm{CO}_{2}\right)$. 
475 Biotinylated anti-mouse IFN-gamma antibody (BD) and streptavidin-Alkaline Phosphotase-

476 substrate (Biolegend) were used to detect IFN-gamma secreting cells. Spot forming cells were

477 enumerated using an Immunospot Analyzer from CTL Immunospot profession software

478 (Cellular Technology Ltd).

479

480 Statistical analyses. Statistical analyses were conducted in Prism (Graphpad) using one-way 481 analysis of variance and Tukey's multiple comparison test used to compare more than two 482 groups, and either student's t or Mann Whitney $U$ tests to compare two groups. Statistical 483 significance was considered when the $p$-values were $<0.05$.

484 Data availability. Data have been deposited in Figshare: 10.6084/m9.figshare.12385574 


\section{Supplemental Figures}

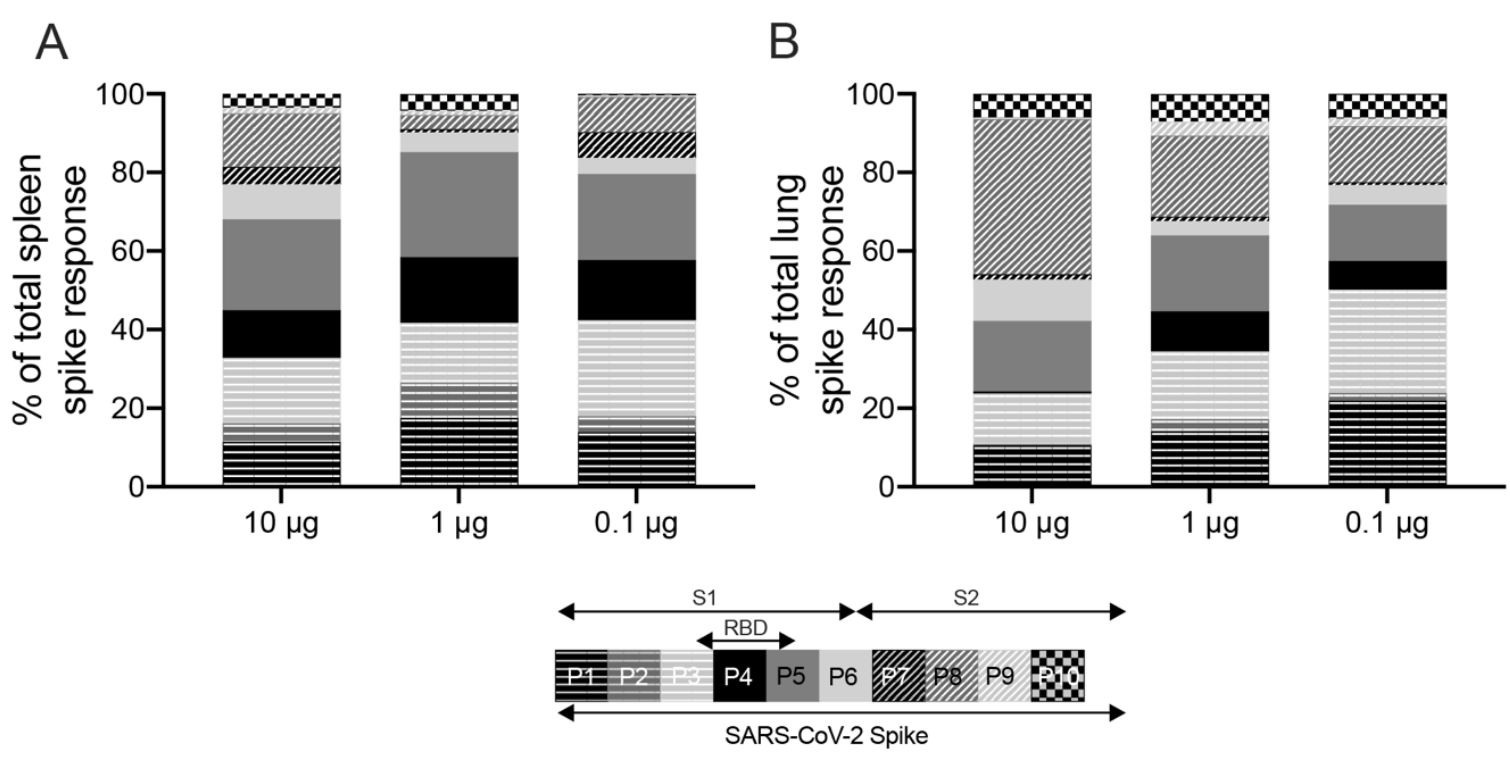

Supplemental Figure 1. Breadth of T-cell responses in C57BL/6 mice. Six to eight-week old C57BL/6 mice ( $n=5 /$ group) received 10,1 , or $0.1 \mu \mathrm{g}$ LION/repRNA-CoV2S via the intramuscular route. On day 28, mice received a booster immunization and 12 days later, (A) spleens and (B) lungs were harvested and IFN- $\gamma$ responses were measured by enzyme-linked immune absorbent spot (ELISpot) following stimulation with 10 peptide pools encompassing the entire Spike protein. Each peptide pool consisted of 26-29 15-mer peptides overlapping by 11 amino acids. Data are presented as percent of total spike response. 


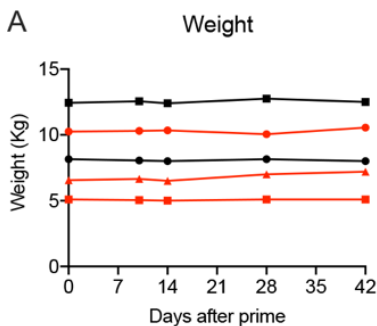

C

ALT

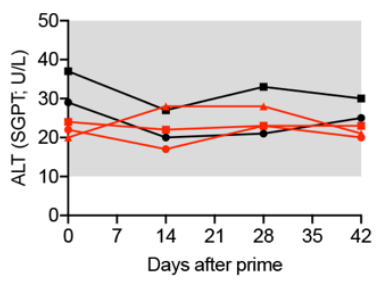

WBC

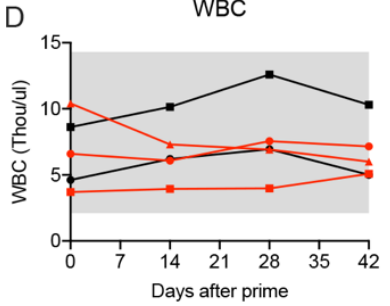

B Body Temperature

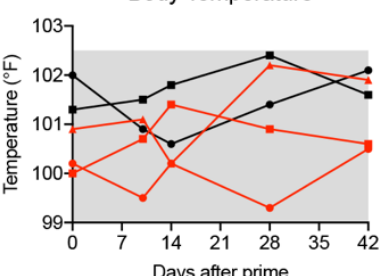

AST
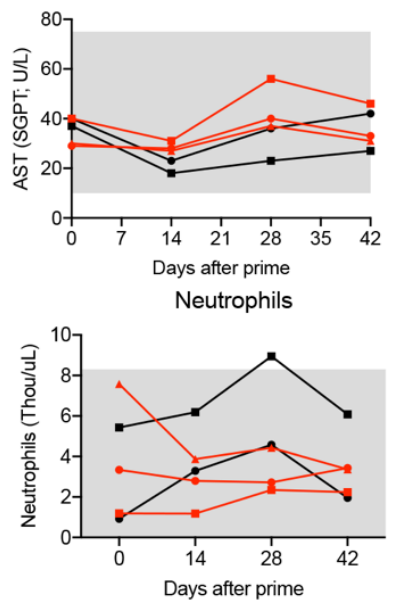

- $\mathrm{Z} 16277$

- Z14176

$\leftarrow \quad$ Z15331

$-\quad$ Z14289

$\rightarrow$ Z15258

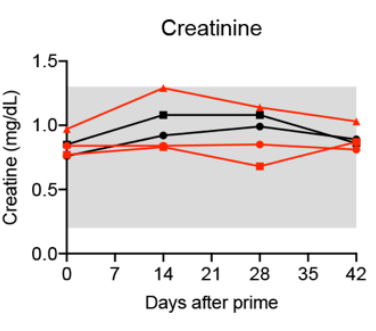

Lymphocytes

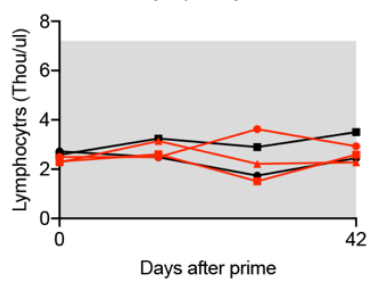

Blood Urea Nitrogen

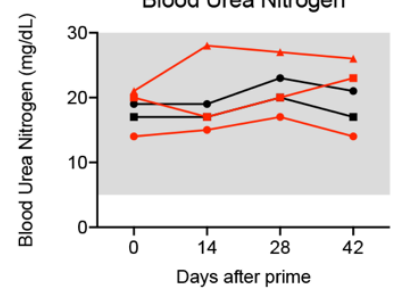

Monocytes

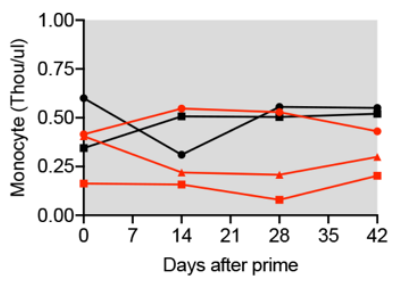

Supplemental Figure 2. Vaccination did not induce adverse reactions in pigtail macaques. (A). Body weight in kg. (B) Rectal body temperature in Fahrenheit. (C) Serum chemistries. (D) Blood complete blood counts (CBC). (A-D) Grey shaded areas indicate normal ranges for pigtail macaques. 


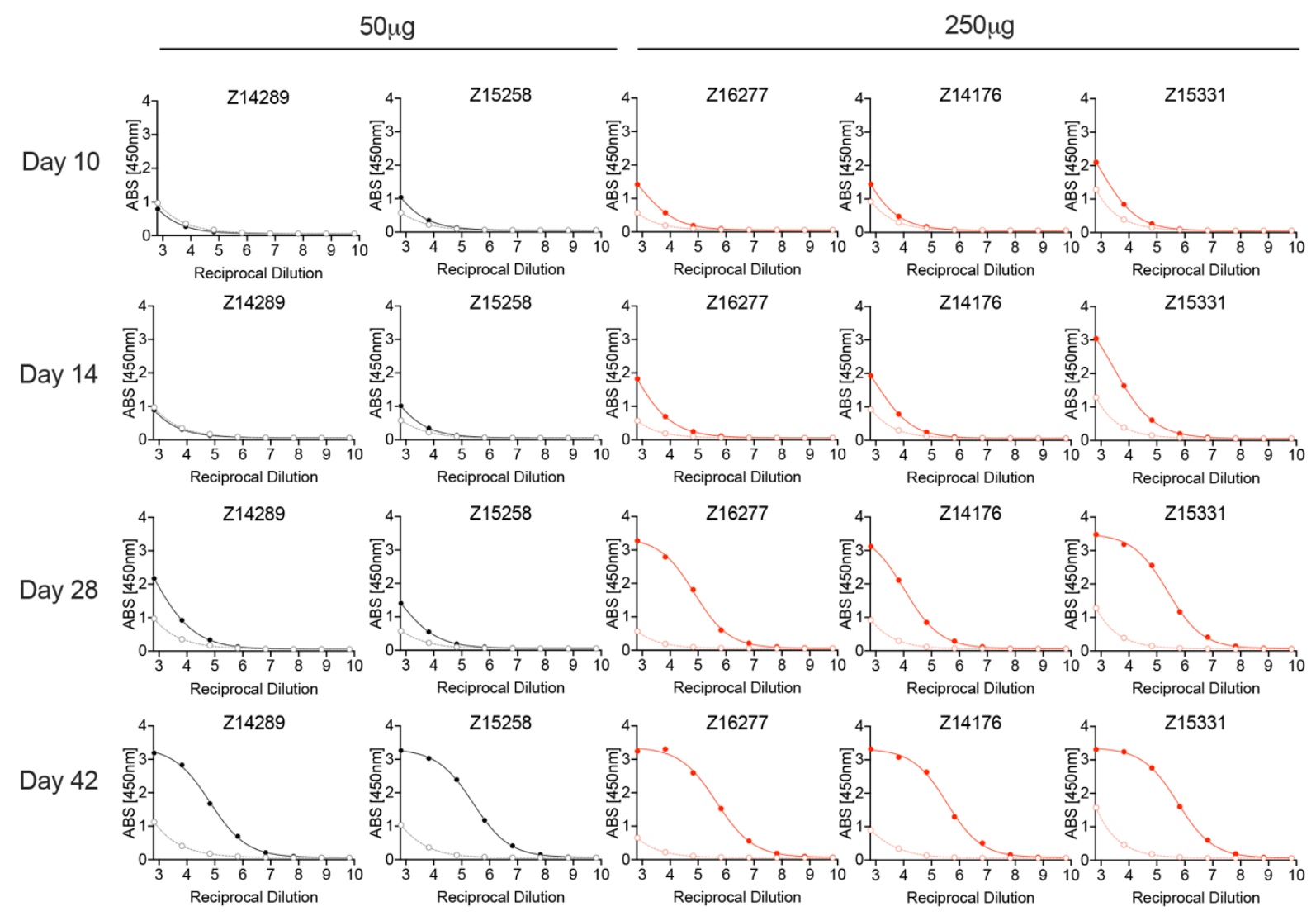

\section{Supplemental Figure 3. Raw ELISA absorbance values from pigtail macaque study. Recombinant}

SARS-CoV-2, based on the Wuhan-Hu-1 isolate, was used as the capture antigen and goat antimonkey IgG-HRP used as the secondary conjugate. Absorbance values were determined at $405 \mathrm{~nm}$.

Data are presented as pre-immune sera (open circles, dotted line) with post-immune sera (closed circles, solid line). Data are presented as pre-immune sera (open circles, dotted line) with postimmune sera (closed circles, solid line). 
bioRxiv preprint doi: https://doi.org/10.1101/2020.05.28.121640; this version posted May 28, 2020. The copyright holder for this preprint (which

was not certified by peer review) is the author/funder, who has granted bioRxiv a license to display the preprint in perpetuity. It is made available under aCC-BY-NC-ND 4.0 International license.
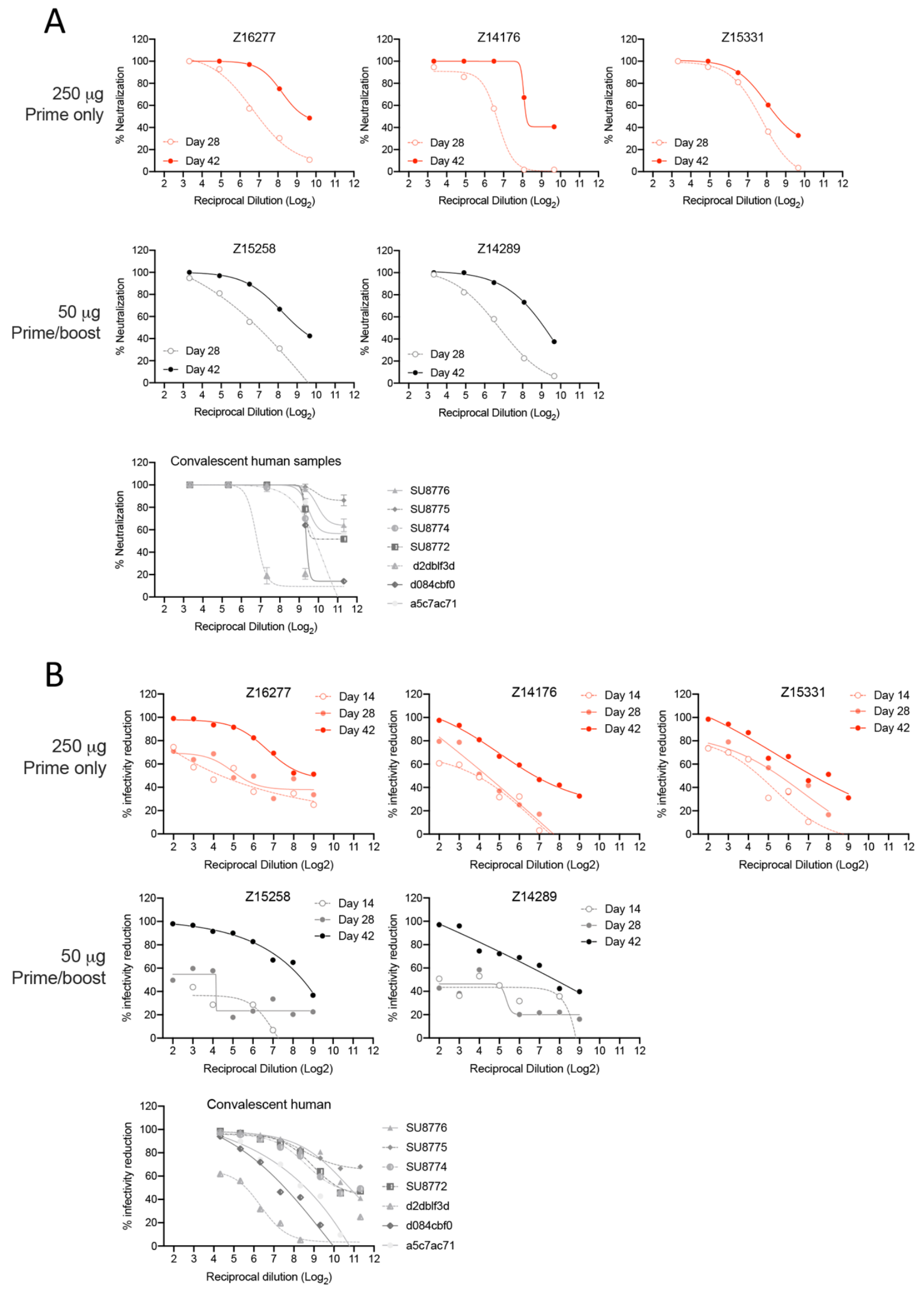


\section{Supplemental Figure 4. Neutralization curves of pigtail macaque and human samples against (A)}

SARS-CoV-2/WA/2020 or (B) pseudotyped virus. SARS-CoV-2/WA/2020 neutralization was

performed on sera collected from macaques on days 28 and 42 post-primary immunization.

Pseudoviral (SARS-CoV-2 Wuhan-Hu-1 pseudotype) neutralization was performed on sera collected

from macaques on days 14, 28, and 42 post-primary. (see Sup. Table 1). Both assays were performed alongside sera from 7 convalescent humans collected at various timepoints after their first positive test for SARS-CoV-2 infection.

Supplemental Table 1. Convalescent sera from COVID-19 patients

\begin{tabular}{ccc}
\hline Sample ID & Days post onset & PRNT $_{\mathbf{8 0}}$ \\
\hline SU8776 & 20 & 1119 \\
SU8775 & 15 & $<20$ \\
SU8774 & 21 & 496 \\
SU8772 & unknown & 635 \\
d2db1f3d & 35 & 88 \\
d084cbf0 & 29 & 607 \\
a5c7ac71 & 64 & 658 \\
\hline \hline
\end{tabular}




\section{Supplemental References}

492 1. Erasmus, J. H. et al. A Nanostructured Lipid Carrier for Delivery of a Replicating Viral RNA

493 Provides Single, Low-Dose Protection against Zika. Mol. Ther. 26, 2507-2522 (2018).

494 2. Chaplin, J. W., Chappell, C. P. \& Clark, E. A. Targeting antigens to CD180 rapidly induces

495 antigen-specific IgG, affinity maturation, and immunological memory. J. Exp. Med. 210,

$496 \quad 2135-2146(2013)$.

497 3. Munson, P. et al. Therapeutic conserved elements (CE) DNA vaccine induces strong T-cell responses against highly conserved viral sequences during simian-human immunodeficiency virus infection. Hum. Vaccin. Immunother. 14, 1820-1831 (2018).

500 4. O'Connor, M. A. et al. Mucosal T Helper 17 and T Regulatory Cell Homeostasis Correlate with Acute Simian Immunodeficiency Virus Viremia and Responsiveness to Antiretroviral Therapy in Macaques. AIDS Res. Hum. Retroviruses 35, 295-305 (2019).

503 5. Walls, A. C. et al. Structure, function and antigenicity of the SARS-CoV-2 spike glycoprotein. bioRxiv 2020.02.19.956581 (2020) doi:10.1101/2020.02.19.956581.

505 6. Millet, J. K. \& Whittaker, G. R. Murine Leukemia Virus (MLV)-based Coronavirus Spikepseudotyped Particle Production and Infection. Bio-protocol 6, e2035 (2016). 